\title{
Dynamics of coworking growth in the real estate market under digitalization
}

\author{
Oksana Pirogova ${ }^{1,{ }^{*}}$ and Nataliia Temnova ${ }^{2}$ \\ ${ }^{1}$ Peter the Great St. Petersburg Polytechnic University, 195251, 29 Polytechnicheskaya str., St. \\ Petersburg, Russia \\ ${ }^{2}$ Herzen State Pedagogical University of Russia, 191186, 48 Moika Embankment, St. Petersburg, \\ Russia
}

\begin{abstract}
The pandemic has affected many sectors of the economy in Russia and the world, and has affected the commercial real estate market. In this situation, approaches to the organization of office space are changing. Currently, the segment of co-working centers is gradually becoming a full-fledged player in the commercial real estate market. The purpose of the study is to analyze the co-working market, forecast growth rates for the coming years and identify development trends. Research objectives: to analyze co-working centers in St. Petersburg; - Build a forecast of the number of co-working centers and identify new trends in the development of co-working spaces in a pandemic. The study used the following methods: descriptions, comparisons, analogies and generalizations, analysis and synthesis, modeling. Based on the data on the growth rates of co-working centers in St. Petersburg, a model for the growth of their number has been built. The research results will make it possible to forecast the development of the co-working center market in the near future.
\end{abstract}

\section{Introduction}

Real estate is the basis of the country's national wealth, which is massive in terms of the number of owners. It also forms the central link of the entire system of market relations. Real estate objects are not only the most important goods that satisfy the personal needs of the owners, but at the same time, they are also income-generating capital.

The increase in demand for commercial real estate leases leads to both an increase in their value and rental rates, which together makes investments in this industry very attractive [1].

The relevance of the study is determined by the fact that the real estate business in the modern world is gaining more and more popularity, since its peculiarity lies in the fact that there are two objects of sale, namely a service and an object [2]. Today, the process of digitalization of the Russian economy has a significant impact on the hospitality industry; in particular, the automation of hotels associated with the use of modern technologies significantly increases the quality of customer service. Digitalization is becoming the main

\footnotetext{
* Corresponding author: kafedra17@,rambler.ru
} 
trend, which is noticeably manifested in the models of distribution of hotel services, and is actively entering the field of automation of internal business processes (communication with customers, distribution of tasks within the team, electronic folders and menus, etc.). Real estate agencies have also been affected by the automation of real estate search. With the emergence of online platforms, sellers and buyers can communicate directly without going through intermediaries. Convenient filters, high speed, which modern technologies allow, made the selection of real estate easier and more accessible even for the average person. Modern electronic systems not only provide detailed information, but also analyze it. Now you can easily find out the market prices for real estate [3]. The market becomes more transparent, barriers to entry are reduced. The growth potential of such online platforms is $93 \%$ per year, and it is difficult for traditional agencies to compete with them in terms of speed and convenience [4].

Highlighting a new socio-economic model such as shared consumption has significantly updated the way goods and services are consumed. Together with the digitalization policy, the sharing economy is actively expanding its spheres of influence and not only improving performance in industries, but transforming economic relations in a variety of areas: urban environment, public transport, intercity transportation, tourism, rental of real estate and equipment (Fig. 1).

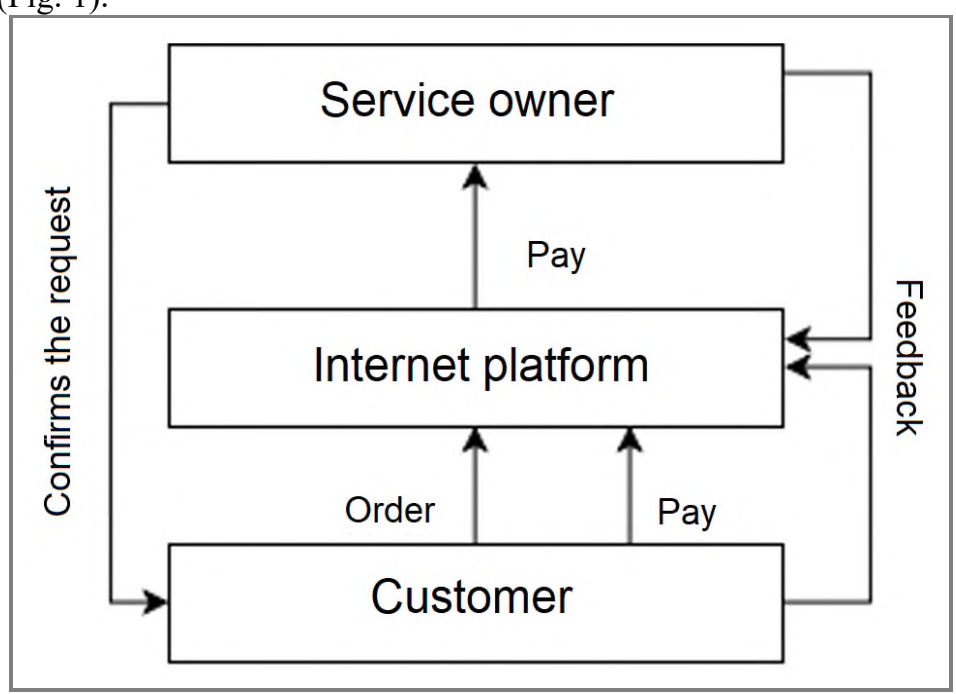

Fig. 1. Sharing consumption model.

Currently, the sharing model in Russia is represented by such platforms as Uber, Bolt, YandexDrive, Delimobil, BlaBlaCar, Avito, Airbnb, Cyan, Yula, YouDo and others. The volume of transactions in 2018 amounted to 511 billion rubles. Figure 2 shows the distribution of sales by sector in Russia for 2018. The main contribution to the volume and growth in the sharing economy is made by $\mathrm{C} 2 \mathrm{C}$ sales ( $72 \%$ of sales) [5].

The increase in the share of shared consumption by more than $30 \%$ is due to the following reasons: a high level of Internet penetration in the country, concentration of demand in large cities and megalopolises, which limits the supply of accommodation facilities and transport, due to the uneven development of the transport system. Currently, many companies have switched to a remote work format. In this regard, there is such a thing as co-working [6]. Now this phenomenon is becoming more and more popular, as the number of stakeholders in this direction in the market is growing. Thus, the purpose of this study is to analyze the co-working market using the example of St. Petersburg and to forecast growth rates for the coming years. 


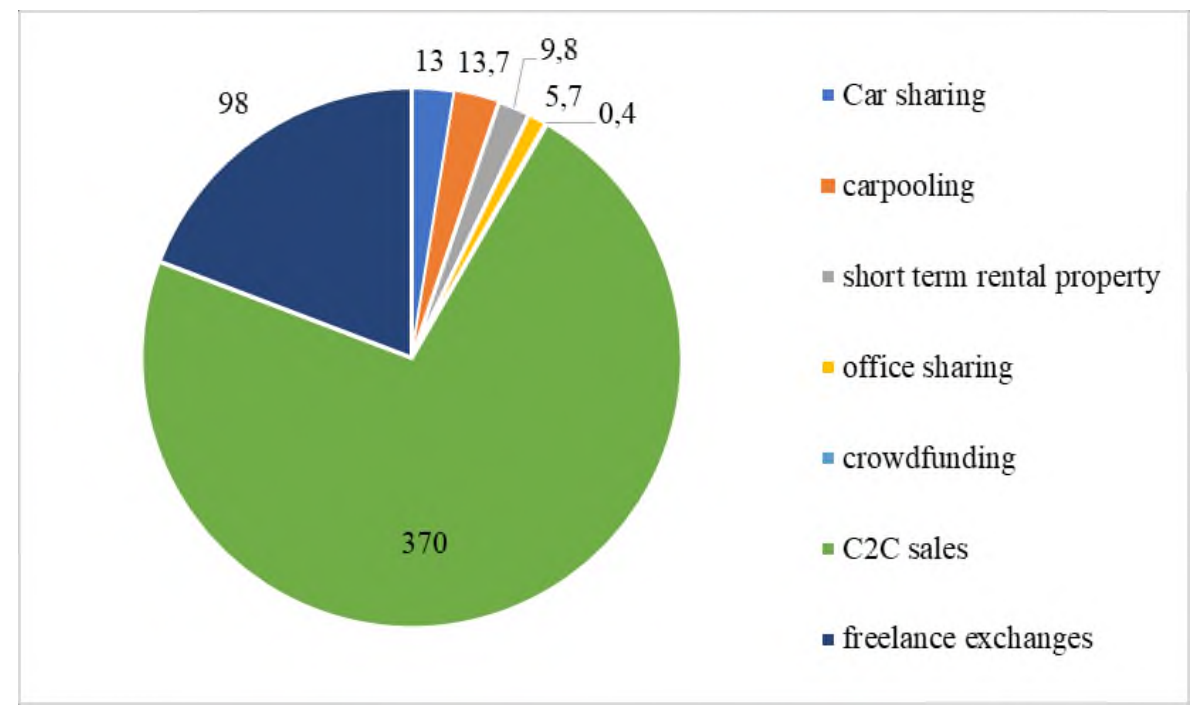

Fig. 2. Volume of transactions by sector, billion rubles in 2018 .

\section{Materials and methods}

Currently, the segment of co-working centers is gradually becoming a full-fledged player in the real estate market. If not long ago, they talked about it as some kind of exotic, creative, but not serious format for big business, then even today such an attitude seems inappropriate.

Co-working is a common space equipped with everything necessary for work, which is rented to any visitor of the center and involves the work of people on a non-competitive basis, in the absence of a business hierarchy. Co-working centers, or co-working spaces, are also called anti-offices [7].

Co-working space is a space that is equipped with everything you need to work and is rented for a short period, namely: a day, a week, a month, and several months [8]. At its core, this is a new alternative to well-known offices. Co-working participants - residents rent a common space that includes several workplaces for their activities or maybe even an entire office. The participants are usually small companies, remote employees, project teams, aspiring entrepreneurs and freelancers (programmers, translators, artists). In addition, in a pandemic situation, this included companies that faced economic difficulties due to the current situation in the country. The rent for a co-working space is made up of several factors, namely: the size of the workplace, the lease term, whether the employee's place is assigned to him or "floating", and the availability of equipment used and the range of services provided [9]. The advantages and disadvantages of co-working are presented in Table 1.

Thus, co-working spaces have many advantages, but there are also a number of disadvantages that you should pay attention to when renting this form of space.

The number of co-working spaces in St. Petersburg increases annually and increases its geography of distribution. Figure 3 shows the distribution of active co-working spaces from 2009 to 2018 [10].

About $60 \%$ of co-working spaces in St. Petersburg are open daily. At the same time, less than $30 \%$ of the objects work around the clock. Only one specialized co-working space operates $24 / 7$. 
Table 1. Comparative analysis of sales channels.

\begin{tabular}{|c|c|}
\hline Advantages & Disadvantages \\
\hline $\begin{array}{c}\text { Free workspace, creating a creative } \\
\text { environment }\end{array}$ & Distracting noise \\
\hline $\begin{array}{c}\text { Flexible rental conditions, which creates a } \\
\text { condition for mobility }\end{array}$ & $\begin{array}{c}\text { Having financial costs in terms of working } \\
\text { from home }\end{array}$ \\
\hline $\begin{array}{c}\text { The presence of additional services that } \\
\text { develop business }\end{array}$ & Travel time compared to working at home \\
\hline $\begin{array}{c}\text { Communication among tenants, new } \\
\text { acquaintances }\end{array}$ & Lack of security of personal belongings \\
\hline
\end{tabular}

All classic co-working spaces offer access to office equipment, internet and cleaning services. Most of them (70-95\%) are equipped with kitchens with drinks / snacks, lockers, meeting rooms, lecture hall / conference hall, recreation areas, offer the possibility of registering legal entities [11].

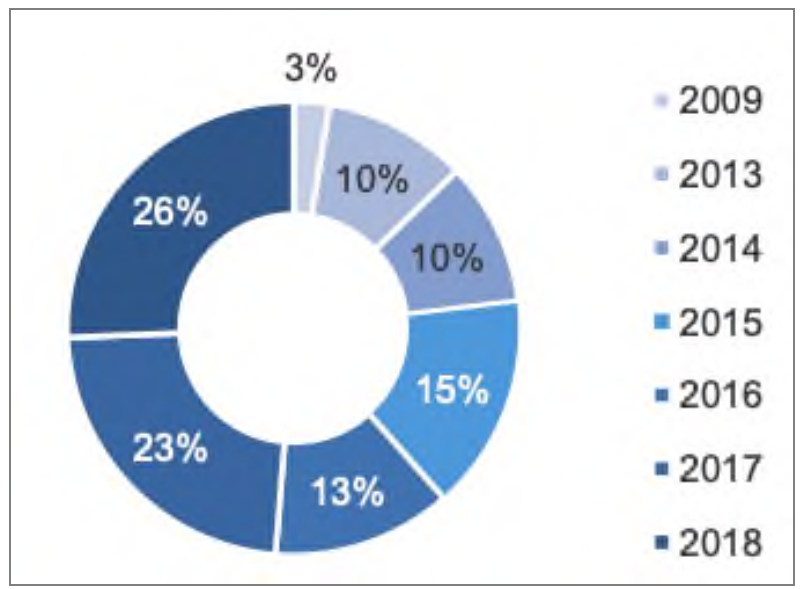

Fig. 3. Distribution of existing co-working spaces by year.

More than half of classic co-working spaces are equipped with mini-offices and offer courier, legal and secretarial support. Approximately 30-40\% of co-working spaces have a play area, a small library, a cafe, showers, and offer accounting services.

Parking is mostly spontaneous (about 60\%), organized parking is usually available for objects located within business centers and shopping centers. For specialized co-working spaces, the most characteristic is the presence of special equipment and the provision of a personal closet for storing things, as well as regular events.

About $50-70 \%$ of specialized co-working spaces have a seating area, a small library with special literature, as well as a lecture hall, equipped with a kitchen with drinks / snacks.

More than $50 \%$ of classic co-working spaces cover an area of over 300 square meters. At the same time, an area of 1000 sq. $\mathrm{m}$ is occupied by almost $25 \%$ of classic co-working spaces. About $90 \%$ of specialized co-working spaces are located on an area of up to 300 square meters, while more than $50 \%$ occupy an area of up to 100 square meters inclusive.

- workplace in a classic co-working space accounts for about 8 square meters of the total area of the object (including MOP), including 4-5 square meters of open space or mini-offices.

- workplace in a specialized co-working space accounts for about 10 square meters of the total area of the facility (including the MOP), including about 6 square meters of open space [12]. 


\section{Results and discussion}

Today there are 69 co-working centers in St. Petersburg. The total area of such spaces is about 50 thousand square meters. These flexible spaces include more than 4.7 thousand workplaces. In 2019, St. Petersburg took second place after Moscow in terms of the number of co-working centers [13]. Speaking about the development trend of co-working spaces in St. Petersburg, presented in Table 2, we note that the growth trend prevails.

Table 2. Dynamics of changes in the number of co-working spaces in St. Petersburg $[13,14]$.

\begin{tabular}{|c|c|c|}
\hline Year & Amount & Growth/decline rate, \% \\
\hline 2015 & 20 & - \\
\hline 2016 & 27 & 35 \\
\hline 2017 & 33 & 22 \\
\hline 2018 & 44 & 33 \\
\hline 2019 & 59 & 34 \\
\hline I H 2020 & 69 & 16 \\
\hline
\end{tabular}

From the data in Table 2, it can be seen that the growth rate of co-working spaces in St. Petersburg has decreased since 2016, but is high. If we compare the number of co-working spaces in 2015 and 2019, then the growth rate will be $195 \%$. Based on this, we can conclude that co-working is rapidly developing in St. Petersburg. The rental of co-working spaces is quite varied. It can be either hourly or monthly. Its cost includes a workplace, office equipment, literature, drinks and the provided service. Average rental rates are presented in table $3[12,13,14]$.

Table 3. Average rental rates for co-working spaces in St. Petersburg in 2019.

\begin{tabular}{|c|c|c|c|}
\hline Object category & Rub/day & $\begin{array}{c}\text { Rub/month } \\
\text { (non-fixed) }\end{array}$ & $\begin{array}{c}\text { Rub/month } \\
\text { (fixed) }\end{array}$ \\
\hline Classic & 500 & 4000 & 9000 \\
\hline Specialized & 1500 & 8000 & 15000 \\
\hline
\end{tabular}

From the data in Table 3 it can be seen that it is much more profitable to rent a coworking space for a long time, if necessary. Co-working centers usually have a convenient location and are located in the central districts of the city within walking distance from metro stations (Figure 4) [14,15].

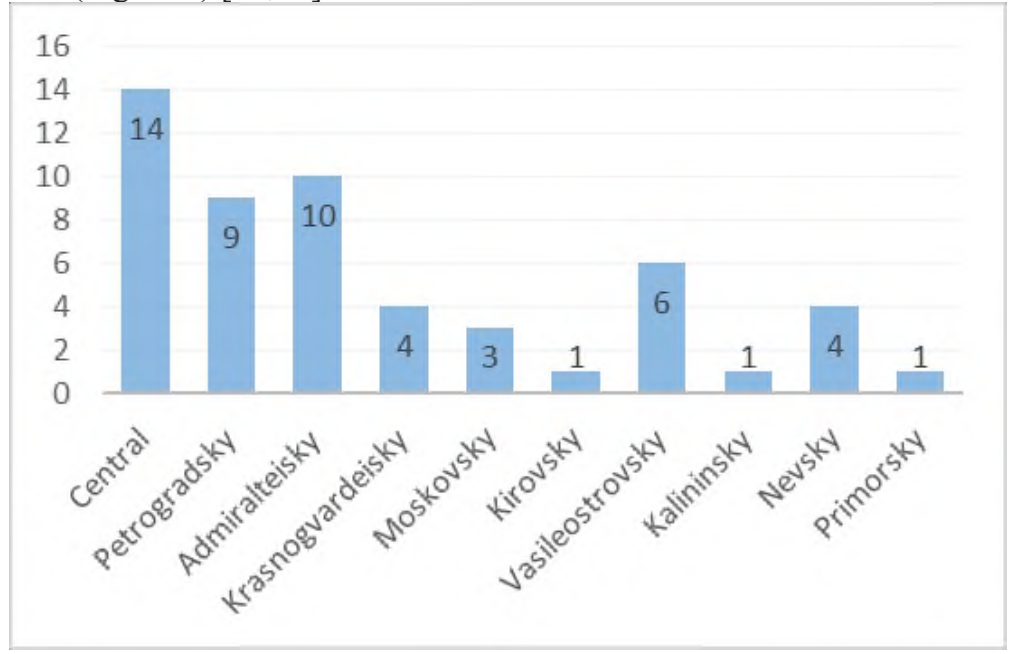

Fig. 4. Distribution of coworking spaces by districts of St. Petersburg for 2019. 
The figure shows that most of the city's co-working spaces are located in the Central, Admiralteisky and Petrogradsky districts. About $26 \%$ of all co-working spaces in the city are concentrated in the Central District. In the Admiralteisky and Petrogradsky districts $19 \%$ and $17 \%$, respectively. Thus, $62 \%$ of St. Petersburg's flexible spaces are concentrated in three districts of the city. According to statistics, the share of co-working spaces in the volume of office real estate in St. Petersburg is 0.3 - 1\% [14]. From this, we can conclude that this market is not developed today, but is just beginning. The offer of co-working spaces is mainly represented by creative spaces. Thus, we can talk about the potential for the development of co-working spaces in St. Petersburg.

Next, we will construct a forecast of the number of coworking centers in St. Petersburg in 2020-2022 using the regression equation shown in Figure 5. The equation of the resulting indicator is as follows:

$$
y=1.5 \times 2+0.5 x+18.6,
$$

where $R^{2}=0.9966$. The dependence is polynomial. $R^{2}$ is an indicator characterizing the reliability of the constructed regression model, the value of the indicator is from 0 to 1 , the closer to 1 , the higher the reliability of the model - the influence of the factor on the resulting indicator is higher.

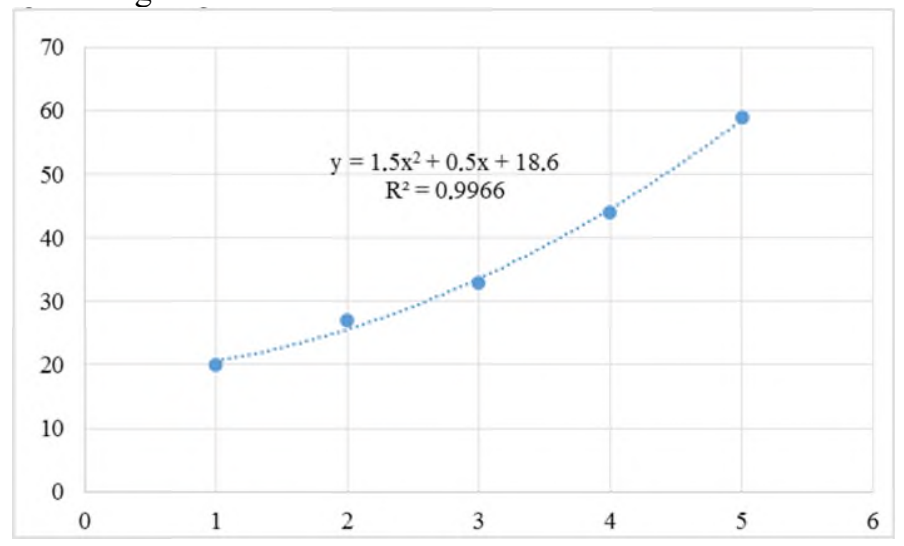

Fig. 5. Dependence of the number of coworking centers in St. Petersburg on the period 2015-2019.

The forecast of the number of co-working centers in St. Petersburg for 2020-2022 and the growth rate are presented in Table 4.

Table 4. Forecast of the number and growth rate of co-working spaces in St. Petersburg 2020-2022.

\begin{tabular}{|c|c|c|}
\hline Year & Amount & $\begin{array}{c}\text { Increase/decrease } \\
\text { rate, } \%\end{array}$ \\
\hline 2020 & 76 & 29 \\
\hline 2021 & 96 & 26 \\
\hline 2022 & 119 & 24 \\
\hline
\end{tabular}

According to the data from Table 4, it can be concluded that the number of co-working centers in St. Petersburg will grow in the next three years, but the growth rate will not be as rapid as before. According to Becar estimates, in 2020 it is planned to enter the market for four large co-working spaces of such a network as Praktik. Their total area will be 13.000 square meters $[15,16]$. 


\section{Conclusion}

At the end of 2019, the St. Petersburg coworking market showed positive dynamics in terms of supply volume, tariffs (from $+2.5 \%$ to $8.5 \%$ ) and occupancy rate (up to $79 \%$ ). Nevertheless, the St. Petersburg market is significantly inferior to the Moscow one in terms of development dynamics. Having such data, we can conclude that the number of coworking will also increase and increase the geography to other areas of the city.

However, it should be noted that this office real estate sector has factors that hinder its development. One of them is the lack of free space in high-quality business centers and, in general, a small amount of free space. Note that not all sectors of the economy need this segment of real estate, but it is in demand mainly among small businesses, which are developing under conditions of uncertainty. The pandemic has brought its own rules to how flexible spaces work. The costs of co-working spaces have increased, as thermometers, masks for residents appeared on the sites, and regular sanitization of premises began to be carried out. The number of events held earlier had to be reduced. Thus, co-working is a complex service, the management of which must be qualified, which is underdeveloped today. The co-working market is developing today, as evidenced by the growth rate of this sector. Development is also forecasted for the coming years, but the growth rate will decrease. However, this segment occupies a very small part of the total volume of office real estate. Development potential is present along with constraining factors that cannot be ignored. In addition, the pandemic gave new directions for the development of this sector, an increase in the number and expansion of the composition of interested groups of coworking centers.

\section{References}

1. A. Ajupov, A. Sherstobitova, S. Syrotiuk, A. Karataev, International Science Conference SPbWOSCE-2018 "Business Technologies for Sustainable Urban Development” 110, 02040 (2019) DOI 10.1051/e3sconf/201911002040

2. A. Sergeev, L. Akhmetshina, K. Grabovyy, International Science Conference SPbWOSCE-2018 "Business Technologies for Sustainable Urban Development" 110, 02153 (2019) DOI 10.1051/e3sconf/201911002153

3. A. Mecke, I. Lee, J.R. Baker jr., M.M. Banaszak Holl, B.G. Orr, Eur. Phys. J. E 14, 7 (2004)

4. O. Kravchenko, M. Leshchenko, D. Marushchak, Y. Vdovychenko, S. Boguslavska, The 8th International Conference on Monitoring, Modeling \& Management of Emergent Economy 65, 07004, (2019) DOI 10.1051/shsconf/20196507004

5. E. Voskresenskaya, L.Vorona-Slivinskaya, L. Achba, Environmental and Resource Economics 164, 09016, (2020) DOI 10.1051/e3sconf/202016409016

6. O. Pirogova, E. Gorin, V. Plotnikov, The algorithms for the environmental finance based on adjusted present value models, E3S Web of Conferences 91, 08021 (2019)

7. V. Plotnikov, O. Pirogova, Key Competencies as an Enterprise Value Management Tool, IBIMA 2018, 1716-1721 (2018)

8. J. Yoshida, The economic depreciation of real estate: Cross-sectional variations and their return implications, Pacific-Basin Finance Journal 61, 101290 (2020) https://doi.org/10.1016/j.pacfin.2020.101290

9. M. Martín-Peña, J. Sánchez-López, E. Díaz-Garrido, Servitization and digitalization in manufacturing: the influence on firm performance, Journal of Business \& Industrial Marketing 35(3), 564-574 (2018) https://doi.org/10.1108/JBIM-12-2018-0400 
10. E. Fang, W.R. Palmatier, J.-B.E. Steenkamp, Effect of Service Transition Strategy on Firm Value, Journal of Marketing 72, 1-14 (2008) https://doi.org/10.1509/jmkg.72.5.1

11. M.M. Hasan, Corporate life cycle, organizational financial resources and corporate social responsibility, Journal of Contemporary Accounting \& Economics 13, 20-36 (2017) DOI: 10.1016/j.jcae.2017.01.002

12. K.M. Bakarich, M. Hossain, J. Weintrop, Different time, different tone: Company life cycle, Journal of Contemporary Accounting and Economics 15(1), 69-86 (2019) https://doi.org/10.1016/j.jcae.2018.12.002

13. O. Pirogova, V. Plotnikov, Z. Popovic, et al. The Multi-level Model of the Service Enterprises Human Capital Value. (Eds.): TransSiberia 2019, AISC 1116, 738-747 (2020) https://doi.org/10.1007/978-3-030-37919-3_73M.

14. A.A. Salisu, I.D. Raheem, U.B. Ndako, The inflation hedging properties of gold, stocks and real estate: A comparative analysis, Resources Policy 66, 101605 (2020) https://doi.org/10.1016/j.resourpol.2020.101605

15. Ya. Li, D. Zhu, J. Zhao, X. Zheng, L. Zhang, Effect of the housing purchase restriction policy on the Real Estate Market: Evidence from a typical suburb of Beijing, China, Land Use Policy 94, 104528 (2020) https://doi.org/10.1016/j.landusepol.2020.104528

16. V. Skribans, M. Jurušs, M. Demianchuk, N. Maslii, D. Pastory, Real estate announcements monitoring dataset for Latvia 2018, Data in Brief. 28, 105064 (2020) https://doi.org/10.1016/j.dib.2019.105064 